\title{
The relationship between sociodemographic variables and depressive symptoms in uncomplicated pregnant women at term
}

\author{
Miadında komplikasyonsuz gebe kadınlarda depresyon belirtilerinin \\ sosyodemografik değişkenlerle ilişkisi
}

\author{
Ebru ERSOY ${ }^{1}$, Halil ÖZCAN² ${ }^{2}$ Ali Özgür ERSOY ${ }^{1}$, Aytekin TOKMAK ${ }^{1}$, Esra YAŞAR ÇELIK ${ }^{1}$, Yasemin TAŞCl ${ }^{1}$
}

ABSTRACT

The aim of this study was to investigate the relationship between sociodemographic variables and depressive symptoms in uncomplicated pregnant women at term. Four hundred-seventeen pregnant patients at term who attended to antenatal outpatient clinic without significant risk factors were recruited for the application of questionnaire survey, and Beck Depression Inventory (BDI). The cut-off point of the scale was evaluated as 17. Accordingly, the patients with $B D I$ scores between 0 and 16 were classified in Group 1, while the other patients were categorized in Group 2. Educational level, occupation, husband's occupation, habitat, social security status, level of financial income, previous psychiatric illness in her or anyone in her family, smoking status, difficulty in arrival to a health center, family structure, migration status, social support provided from her family and close environment, the number of her marriages, the status of planned or unplanned pregnancy, the outcome of previous pregnancy, the use of vitamin pills in pregnancy, conceiving with a medical treatment (except in vitro fertilization), and number of parities were not significantly different between groups. The presence of anxiety for fetal health, unfavorable life experience, marital problems, history of premenstrual syndrome, the lower birth weights, and the absence of a civil marriage and regular antenatal visits in Group 2 were significantly more frequent than Group 1. As a conclusion; many individual variables of uncomplicated pregnants at term can induce the development of depressive symptoms. The early recognition of the risk factors that aggravate depressive mood of the pregnants may aid in taking measures aiming to improve maternal and neonatal heath state.

Keywords: Pregnancy; depression; questionnaire; maternal health

GiRiş

Gebelik, kadın hayatında önemli biyolojik, psikolojik ve sosyal değişikliklerin yaşanabildiği bir dönemdir. öz

Çalışmanın amacı, antenatal risk faktörü bulunmayan term gebeliklerde, sosyodemografik etkenler ile depresyon belirtilerinin ilişkisini araștırmaktı. Ayaktan başvuran hastalar arasından katılım sağlayan 417 miadında, antenatal takiplerinde belirgin risk saptanmayan gebeye anket ve Beck Depresyon Ölçeği (BDÖ) uygulandı. Ölçekte kesme puanı 17 olarak değerlendirildi. Buna göre, BDÖ puanı 0-16 olanlar 1. grup, 17 ve üzeri olanlar 2. grup olarak sınıflandırıldı. Katılımcıların eğitim düzeyi, kendisinin mesleği, eşinin mesleği, yaşam yeri, sosyal güvence, aylık gelir, geçmişte psikiyatrik hastalık öyküsü, ailede psikiyatrik hastalık öyküsü, sigara kullanımı, sağlık kuruluşuna ulaşım zorluğu, aile yapısı, göç etme, ailenin gebeye sosyal desteği, çevrenin gebeye sosyal desteği, gebenin kaçıncı evliliği olduğu, gebeliğin planlanarak istenmesi, önceki gebelik sonucu, gebelikte vitamin kullanımı, tedavi gebeliği (tüp bebek hariç) varlığı ve parite açısından gruplar arasında anlamlı fark saptanmadı. Bebek ile ilgili kaygı varlığı, olumsuz yaşam deneyimi varlığı, evlilikte sorun varlığı, resmi nikâh yokluğu, düzenli antenatal takip yokluğu, premenstrüel sendrom öyküsü varlığı ve bebeğin doğum ağırlığının daha az olması 2. grupta istatistiksel olarak belirgin derecede fazla gözlendi. Sonuç olarak, gebelik süreci sağlıklı ilerleyen doğuma yakın olgularda da değişik bireysel özellikler depresyon semptomları gelişimine neden olabilmektedir. Bu gebelerin deprese ruh hâlini arttırabilecek faktörlerin önceden tanınması, anne ve çocuk sağı̆ğını iyileştirici önlemlerin alınmasına yardımcı olabilir.

Received: 07.04.2016

Accepted: 06.06.2016

${ }^{1}$ Department of Obstetrics and Gynecology, Zekai Tahir Burak Women's Healthcare, Training and Research Hospital

${ }^{2}$ Department of Psychiatry, Ataturk University

Yazışma adresi: Ebru Ersoy, Department of Obstetrics and Gynecology, Zekai Tahir Burak Women's Healthcare, Training and Research Hospital, Ankara

e-mail: eebruersoy09@gmail.com 
sonrası 6. haftada son bulur. Reprodüktif dönem kadınlarında olağan fizyolojinin (menstrüel siklus) dışında gelişen bir dönem olarak gebelik, kadında algısal ve psikolojik değişkenliğe neden olabilmektedir. Yapılan çalışmalar, depresyonun 18-44 yaş arasındaki reprodüktif çağ kadınlarında önemli oranlarda görüldüğünü bildirmektedir ${ }^{1,2}$. Sistematik bir derlemede, gebelik döneminde depresyon sıklığının, birinci, ikinci ve üçüncü trimesterde sırasıyla, $\% 7,4, \% 12,8$ ve $\% 12$ olduğu bildirilmiştir ${ }^{3}$. Yine, gebelikte ve doğum sonrası dönemde depresyonu inceleyen bir derlemede, gebelerin \%70'inden fazlasında depresif belirtilerin olduğu ve \%10-16 oranında major depresyon bulunduğu bildirilmiştir ${ }^{4}$.

Kadınlar tarafından gebelik, mutluluk, doyum, olgunluk, kendini gerçekleştirme olarak algılanabileceği gibi, aynı zamanda stres, endişe, kaygılı bekleyiş gibi olumsuz ruhsal duygulanımların yaşanabileceği bir dönem olarak da görülebilmektedir. Bireyler arasındaki farklı etkenler, gerek gebelik, gerekse doğum sonrası depresyon gelişimine neden olabilmektedir. $\mathrm{Bu}$ nedenle gebelik, depresyon belirtilerinin eşlik edebileceği, kadının yaşamında önemli bir dönemdir $^{5}$. Ülkemizde, gebelik döneminde depresyon gelişimi ile ilgili sınırlı sayıda çalışma bulunmaktadır. Erken dönemde depresyon belirtilerine sahip gebelerin sağlık hizmeti veren personel tarafından tanınması ve destek sağlanması, olası bir postpartum depresyonu engelleyebilir 6 . Bu bağlamda, çalışmamızda, hastaneye ayaktan başvuran, antenatal takiplerinde risk faktörü bulunmayan, miadında gebelerde, depresyon semptomlarının sıklığı ve sosyodemografik etkenler ile depresyon belirtilerinin ilişkisini araştırmayı amaçladık.

\section{GEREÇ ve YÖNTEM}

Kesitsel ve ölçekli anket çalışmamıza, Ankara'da referans bir merkez olan Zekai Tahir Burak Kadın Sağlığı Eğitim ve Araştırma Hastanesi'ne Aralık 2013-Mayıs 2014 tarihleri arasında ayaktan başvuran ve çalışmaya katılmayı kabul eden 417 gebe dâhil edilmiştir. Çalışma öncesinde, hastanemizin Eğitim Planlama ve Koordinasyon Kurulundan gerekli onay alınmıştır
(Onay tarih ve numarası: 23.08.2013/35). Araştırmanın planlanması ve yürütülmesinde, 2008 yılında güncellenmiş olan Helsinki Deklerasyonu ilkelerine uyulmuştur. Katılımcılar doğumun aktif evresinde olmayan, gebelik haftası son adet tarihine (SAT) göre 37 hafta ve üzerinde olup, antenatal takipte belirlenmiş risk faktörü bulunmayan, çoğul gebeliği olmayan, tüp bebek tedavisi ile gebe kalmamış, gebelikte ilaç kullanımı olmayan (vitamin ve demir preparatı hariç) ve kronik hastalığı bulunmayan gebelerden oluşturuldu. Soruları net olarak yanıtlayamayan ve okur-yazar olmayan bireyler çalışma dışı bırakıldı. Katılımcılara anket çalışması hakkında bilgi verildi ve yazılı onam veren gebeler çalışmaya dâhil edildi. Ekonomik gelir düzeyi, 2012 yılı Türkiye İstatistik Kurumunun kişi başı gelir üzerinden belirlediği değerlere göre sınıflandırıldı. Göç durumu, son 1 yıl içinde yaşadığı şehrin değişmesi olarak sorgulandı. Son 1 yıl içinde kişiyi derinden etkilemiş olay (ölüm, kaza, vb. gibi) varlığı "olumsuz yaşam deneyimi" olarak değerlendirildi. Katılımcılara sosyodemografik form soruları yazarlar tarafından sorgulanıp, ardından Beck Depresyon Ölçeği (BDÖ) formu yazar gözetiminde kişilerin kendisi tarafından dolduruldu.

\section{Beck Depresyon Ölçeği}

Bin dokuz yüz altmış bir yılında geliştirilmiş olan ölçek, depresyonda görülen belirtileri araştıran, 0-3 arasında puanlanan, 21 adet kendini değerlendirme maddesinden oluşmaktadır ${ }^{7}$. Ölçek, depresyon tanısından daha çok, depresif belirtilerin şiddetini değerlendirmektedir. Alınan puan 0-9 arasında ise kişide büyük olasılıkla depresyon olmadığı, 10-16 puan ise hafif düzeyde, 17-24 puan ise orta, 25 ve üzeri ise şiddetli düzeyde depresif belirtilerin olduğu düşünülmektedir. Ölçeğin Türkçe uyarlaması, geçerlilik ve güvenilirlik çalışması Hisli tarafından yapılmış ve kesme puanı 17 olarak bildirilmiştir ${ }^{8}$. Ölçekten 17 ve üzeri puan alınması, \%90 doğrulukla kişide tedavi gerektirecek düzeyde depresif belirtilerin olduğunu düşündürmektedir ${ }^{9}$. Bu nedenle BDÖ puanı 0 ile 16 arası olan olgular 1. grup, BDÖ puanı 17 ve üzeri olgular 2 . grup olarak düzenlendi. 


\section{İstatistiksel Değerlendirme}

Çalışmada elde edilen veriler değerlendirilirken, istatistiksel analizler icin SPSS (Statistical Package for Social Sciences) for Windows version 17.0 yazılımı kullanılmıştır. Tüm katılımcıların demografik verileri, normal dağılıma uygun olanlarda ortalama standart sapma değerleri ile verilip, gruplar arası karşılaştırmaları Student's t test ile yapıldı. Normal dağılmayan veriler ortanca (minimum-maksimum) değerleri ile verilip, gruplar arasında Mann-Whitney $U$ testi ile karşılaştırıldı. Kategorik veriler sayı ve yüzde değerleri ile sunulup, ki-kare veya Fisher'ın kesin testi ile karşılaştırıldı. İstatistiksel anlamlılık düzeyi $p<0,05$ olarak alınmıştır.

\section{BULGULAR}

Çalışmamıza katılan 417 olgunun yaş dağılımı $26,53 \pm 5,51$ yıl, ortanca evlilik süresi 4,5 yıl olarak izlenmiştir. Daha önce herhangi bir gebelik öyküsü (düşük, doğum ve küretaj) olan 267 kadının mevcut gebeliği ile bir önceki gebeliği arası süre ortanca 4 yıl olarak saptanmıştır. Tüm hastaların demografik verileri Tablo 1'de özetlenmiştir. Katılımcıların ortanca BDÖ puanı 9 olup, 1. grupta (0-16 puan) $346(\% 82,98)$ kişi, 2. grupta (17 ve üzeri puan) $71(\% 17,02)$ kişi yer almıştır. Bebeklerin doğum ağırlığı 2. grupta anlamlı olarak daha düşük saptandı $(p=0,029)$, diğer parametrelerde anlamlı farklılık saptanmadı (Tablo 2).

Tablo 1. Tüm hastaların demografik verileri.

\begin{tabular}{ll}
\hline Değişken & Dağılım \\
\hline Yaş (yıl) & $26,53 \pm 5,51$ \\
Evlilik süresi (yıl) & $4,5(0,5-26)$ \\
Bir önceki gebelikten sonra geçen süre (yıl)* & $4(0-22)$ \\
Doğumda gebelik haftası & $39,37 \pm 1,29$ \\
Doğum ağırlığı (g) & $3351,1 \pm 399,09$ \\
Beck depresyon puanı & $9(0-42)$ \\
Gebelik sayısı & $2(0-9)$ \\
Doğum sayısı & $1(0-4)$ \\
Yaşayan çocuk sayısı & $1(0-4)$ \\
Düşük sayısı & $0(0-4)$ \\
Elektif küretaj sayısı & $0(0-3)$ \\
\end{tabular}

*Daha önce gebelik geçirmiş 267 hasta için değerlendirildi.
Tablo 2. BDÖ puanına göre iki grubun demografik verilerinin kıyaslaması.

\begin{tabular}{llll}
\hline Değişken & $\begin{array}{l}\text { BDÖ puanı } \\
\mathbf{0 - 1 6}(\mathbf{n = 3 4 6 )}\end{array}$ & $\begin{array}{l}\text { BDÖ puanı 17 } \\
\text { ve üzeri }(\mathbf{n = 7 1 )}\end{array}$ & $\begin{array}{l}\mathbf{p} \\
\text { değeri }\end{array}$ \\
\hline Yaş (yıl) & $26,51 \pm 5,39$ & $26,61 \pm 6,07$ & 0,893 \\
Evlilik süresi (yıl) & $7(1-26)$ & $7(1-22)$ & 0,776 \\
Bir önceki gebelikten & $3(0-22)$ & $4(0-15)$ & 0,333 \\
sonra geçen süre (yıl)* & & & \\
Doğumda gebelik haftası & $39,39 \pm 1,28$ & $39,3 \pm 1,3$ & 0,593 \\
Doğum ağırlığı (g) & $3370 \pm 398$ & $3256 \pm 392$ & 0,029 \\
Beck depresyon puanı & $8(0-16)$ & $22,5(17-42)$ & $<0,001$ \\
Gebelik sayısı & $2(1-9)$ & $3(2-7)$ & 0,131 \\
Doğum sayısı & $1(0-4)$ & $1(0-4)$ & 0,430 \\
Yaşayan çocuk sayısı & $1(0-4)$ & $1(0-4)$ & 0,332 \\
Düşük sayısı & $0(0-4)$ & $0(0-3)$ & 0,315 \\
Elektif küretaj & $0(0-2)$ & $0(0-3)$ & 0,156 \\
\hline
\end{tabular}

*Daha önce gebelik geçirmiş 267 hasta için değerlendirildi.

Katılımcıların eğitim düzeyi, kendisinin mesleği, eşinin mesleği, yaşam yeri, sosyal güvence, aylık gelir, geçmişte psikiyatrik hastalık öyküsü, ailede psikiyatrik hastalık öyküsü, sigara kullanımı, sağlık kuruluşuna ulaşım zorluğu, aile yapısı, göç etme, ailenin gebeye sosyal desteği, çevrenin gebeye sosyal desteği, gebenin kaçıncı evliliği olduğu, gebeliğin planlanarak istenmesi, önceki gebelik sonucu, doğum şekli, bebek cinsiyeti, gebelikte vitamin kullanımı, tedavi gebeliği (tüp bebek hariç) varlığı ve parite açısından gruplar arasında anlamlı fark saptanmadı (Tablo 3). Öte yandan, bebek ile ilgili kaygı varlığı $(p=0,047)$, olumsuz yaşam deneyimi varlığı $(p=0,013)$, evlilikte sorun varlığı $(p=0,003)$, resmi nikah yokluğu $(p<0,001)$, düzenli antenatal takip yokluğu $(p=0,014)$ ve gebelik öncesinde premenstrüel sendrom öyküsü $(p<0,001)$ değişkenlerinin, grup 2'de istatiksel açıdan daha belirgin olduğu saptandı (Tablo 3).

\section{TARTIŞMA}

Çalışmamızda, antenatal dönemde belirgin risk faktörü olmayan gebelerin miad dönemde depresyon belirtilerinin sıklığı ve bununla ilişkili sosyodemografik değişkenler incelenmeye çalışılmıştır. Ülkemizde yapılan benzer çalışmalarda, antenatal dönemde risk saptanıp saptanmamasına göre hastaların ayırt edilmediği gözlenmektedir ${ }^{10-12}$. Antenatal dönemde risk belirlenmiş gebe, bebeği ile ilgili artmış kaygı varı̆ğının beraberinde BDÖ puanını arttırabileceği için, 
Tablo 3. Kategorik değişkenlerin iki grup arasında kıyaslanması.

\begin{tabular}{|c|c|c|c|c|c|c|c|}
\hline Değişken & $\begin{array}{l}\text { BDÖ puanı } \\
0-16(n=346, \\
\% 82,98)\end{array}$ & $\begin{array}{l}\text { BDÖ puanı } \\
17 \text { ve üzeri } \\
(n=71, \% 17,02)\end{array}$ & $\begin{array}{l}\text { p } \\
\text { değeri }\end{array}$ & & & & \\
\hline Eğitim düzeyi & & & & Göç varlığı (şehir dışı) & & & \\
\hline ilkokul & $87(25,1)$ & $19(26,8)$ & & Var & $79(22,8)$ & $13(18,3)$ & 0,403 \\
\hline Ortaokul & $103(29,8)$ & $24(33,8)$ & 0,600 & Yok & $267(77,2)$ & $58(81,7)$ & \\
\hline Lise & $126(36,4)$ & $25(35,2)$ & & Ailenin sosyal desteği & & & \\
\hline Yükseköğretim & $30(8,7)$ & $3(4,2)$ & & Var & $274(79,2)$ & $54(76,1)$ & \\
\hline Meslek durumu & & & & Yok & $72(20,8)$ & $17(23,9)$ & 0,557 \\
\hline Ev hanımı & $293(84,7)$ & $64(90,1)$ & & & & & \\
\hline İşçi & $33(9,5)$ & $2(2,8)$ & 0,268 & Çevrenin sosyal destek & & & \\
\hline Memur & $11(3,2)$ & $2(2,8)$ & & Var & $205(59,2)$ & $44(62)$ & 0,670 \\
\hline Serbest meslek & $9(2,6)$ & $3(4,2)$ & & Yok & $141(40,8)$ & $27(38)$ & \\
\hline Eşinin mesleği & & & & Resmi nikâh & & & \\
\hline İşsiz & $27(7,8)$ & $4(5,6)$ & & Var & & & \\
\hline İşçi & $185(53,5)$ & $33(46,5)$ & 0,380 & Yok & $343(99,4)$ & $68(95,8)$ & $<0,001$ \\
\hline Memur & $29(8,4)$ & $5(7)$ & & Kaçıncı evlilik & $2(0,6)$ & $3(4,2)$ & \\
\hline Serbest meslek & $105(30,3)$ & $29(40,8)$ & & illk & & & \\
\hline Yaşam yeri & & & & İkinci & $340(98,3)$ & $71(100)$ & 0,264 \\
\hline Köy & $10(2,9)$ & $5(7)$ & & Çiftin gebelik istemi & $6(1,7)$ & 0 & \\
\hline İlçe & $80(23,1)$ & $15(21,1)$ & 0,227 & Yalnız kadın istemiş & & & \\
\hline İl merkezi & $256(74)$ & $51(71,8)$ & & Yalnız erkek istemiş & $13(3,8)$ & $2(2,8)$ & \\
\hline Sosyal güvence & & & & İkisi de istemiş & $21(6,1)$ & $9(12,7)$ & 0,119 \\
\hline Var & $323(93,4)$ & $62(87,3)$ & 0,082 & İstenmeyen gebelik & $240(69,4)$ & $41(57,7)$ & \\
\hline Yok & $23(6,6)$ & $9(12,7)$ & & Önceki gebelik sonucu & $72(20,8)$ & $19(26,8)$ & \\
\hline Aylık gelir & & & & Önce gebelik yok & & & \\
\hline Düşük & $62(17,9)$ & $15(21,1)$ & & Doğum & $136(39,3)$ & $27(38)$ & \\
\hline Orta & $260(75,1)$ & $52(73,2)$ & 0,777 & Düşük & $159(46)$ & $36(50,7)$ & 0,667 \\
\hline Yüksek & $24(6,9)$ & $4(5,6)$ & & Doğum şekli & $51(14,7)$ & $8(11,3)$ & \\
\hline Psikiyatrik öykü & & & & Vajinal doğum & & & \\
\hline Var & $21(6,1)$ & $8(11,3)$ & 0,117 & Sezaryen doğum & $235(67,9)$ & $55(77,5)$ & 0,111 \\
\hline Yok & $325(93,9)$ & $63(88,7)$ & & Bebek cinsiyeti & $111(32,1)$ & $16(22,5)$ & \\
\hline Ailede psikiyatrik öykü & & & & Erkek & & & \\
\hline Var & $32(9,2)$ & $6(8,5)$ & 0,831 & $\mathrm{~K} \mathrm{IZ}$ & $172(49,7)$ & $31(43,7)$ & 0,353 \\
\hline Yok & $314(90,8)$ & $65(91,5)$ & & Gebelikte vitamin & $174(50,3)$ & $40(56,3)$ & \\
\hline Sigara kullanımı & & & & Kullanmış & & & \\
\hline Var & $37(10,7)$ & $13(18,3)$ & 0,072 & Kullanmamış & $316(91,3)$ & $62(87,3)$ & 0,291 \\
\hline Yok & $309(89,3)$ & $58(81,7)$ & & Düzenli antenatal takip & $30(8,7)$ & $9(12,7)$ & \\
\hline Bebek ile ilgili kaygı & & & & Var & & & \\
\hline Var & $66(19,1)$ & $21(29,6)$ & 0,047 & Yok & $326(94,2)$ & $61(85,9)$ & 0,014 \\
\hline Yok & $280(80,9)$ & $50(70,4)$ & & Tedavi gebeliği & $20(5,8)$ & $10(14,1)$ & \\
\hline Ulaşım zorluğu & & & & Yok & & & \\
\hline Var & $21(6,1)$ & $4(5,6)$ & 0,888 & Var & $338(97,7)$ & $71(100)$ & 0,196 \\
\hline Yok & $325(93,9)$ & $67(94,4)$ & & Premenstruel sendrom & $8(2,3)$ & 0 & \\
\hline Olumsuz yaşam deneyimi & & & & öyküsü & & & \\
\hline Var & $33(9,5)$ & $14(19,7)$ & 0,013 & Var & & & \\
\hline Yok & $313(90,5)$ & $57(80,3)$ & & Yok & $96(27,7)$ & $39(54,9)$ & $<0,001$ \\
\hline Evlilikte sorun & & & & Parite & $250(72,3)$ & $32(45,1)$ & \\
\hline Var & $19(5,5)$ & $11(15,5)$ & 0,003 & Nulliparite & & & \\
\hline Yok & $327(94,5)$ & $60(84,5)$ & & Multiparite & $157(45,4)$ & $32(45,1)$ & 0,962 \\
\hline Aile yapısı & & & & & $189(54,6)$ & $39(54,9)$ & \\
\hline Çekirdek & $268(77,5)$ & $53(16,5)$ & 0,609 & & & & \\
\hline Geniş & $78(22,5)$ & $18(25,4)$ & & & & & \\
\hline
\end{tabular}

çalışmamızda sağlık sorunlarına (anne ve/veya bebek ile ilgili) bağı ıtkenlerin dışında annede deprese semptomları etkileyen faktörleri belirlemeyi hedefle- dik. Gebeliği sağlıklı ilerleyen olgularda da, değişik bireysel özelliklerin depresyon semptomları gelişimine neden olabileceğini gördük. 
Sosyodemografik verilere bakıldığında, örneklem grubunun ağırlıklı olarak ortaöğretim düzeyinde ve sosyoekonomik düzeyi düşük-orta kesimden oluştuğu söylenebilir. Araştırmamızdaki BDÖ puanlarına bakıldığında, tüm gebelerin yaklaşık olarak \%17'sinin orta-ağır şiddette depresif belirtilere sahip olduğu bulunmuştur. Bu sonuç, gebelerin \%70'inden fazlasında depresif belirtilerin olduğu, \%10-16'sının ise major depresyonu olduğu sonucuna ulaşan önceki bir derleme ile uyumlu görünmektedir ${ }^{4}$. Literatürde depresyon belirtileri açısından önemli olduğu bildirilen, geçirilmiş depresyon, ailede depresyon öyküsü, sosyal destek azlığı gibi sosyodemografik değişkenler açısından, çalışmamızda gruplar arasında fark bulunmamıştır ${ }^{13,14}$. Öte yandan, iki grubun sayısal olarak eşitlenmesi hâlinde, bu parametrelerin yeniden değerlendirilmesi sonucu etkileyebilir.

Doğum ve fetusun sağlığı ile ilgili kaygılar, evlilik sorunlarının varlığı, önceki çalışmalara benzer şekilde, gebelerde depresyon belirtileri açısından önemli olarak bulunmuştur ${ }^{11}$. Çalışmamızda, istatistiksel olarak belirgin olmasa da, sigara içen gebelerde depresif belirtiler daha sık bulunmuştur. Aubin ve ark. ${ }^{15}$ tarafından daha önce yapılan bir çalışma da, bu bulgumuzu desteklemektedir. Ülkemizde doğumların yaklaşık \%20'si plansız gebelik sonucu gerçekleşmektedir ${ }^{16}$. Bu parametrenin gruplarımız arasında anlamlı farkıılık sergilememesinin, çoğu kadının gebelik süreci içerisinde durumu kabullenmesinden kaynaklanmış olabileceğini düşündük.

Düzenli antenatal takiplere devam etmemiş olmak, doğuma yakın zamanda olasılıkla bebek ile ilgili kaygıları arttırarak, depresif belirtilerin artmasına neden olmaktadır. Çalışmamızdaki resmi nikâhı bulunmayan kadınların daha yoğun depresif belirtiler göstermesi, benzer şekilde kişinin kendini ve bebeğini güvencede hissedememesine bağlanabilir ${ }^{17}$. Premenstrüel sendrom öyküsünün varlığı, diğer bazı çalışmalarda da gösterildiği gibi, bizim çalışmamızda da depresyon ile ilişkili bulunmuştur ${ }^{18,19}$.

Gebelikteki depresyonların bir kısmının doğum sonrasında devam ettiği, gebelik depresyonunun gebe- nin özkıyımı da dâhil olmak üzere gebe, fetüs, yenidoğan ve ailenin sağlığına olumsuz etkileri olduğu, gebelik döneminde depresyonu olanlarda doğum sonrası depresyon riskinin belirgin arttığı ve bu durumların çocuğun ileri yaşamında anne-bebek bağının kurulmasında sorunların oluşması, büyümede gerilik, motor ve dil gelişiminde gecikme, duygusal gelişimde bozukluk ve davranış sorunları gibi olumsuz etkilerinin olabileceği bildirilmektedir ${ }^{20}$.

Gebelik döneminde depresyon tanınır ve etkili biçimde tedavi edilirse, postpartum depresyonun önlenmesi de olası görünmektedir 6 . Bu bağlamda, ciddi sonuçları olabilen gebelik depresyonunun önlenmesi, korunması, teşhis ve tedavisinde ebe, hemşire, kadın hastalıkları ve doğum uzmanları ile ruh sağlığı çalışanlarının birlikte çalışmaları çok önemlidir ${ }^{12}$. Ülkemizde "gebe okulları" başlığı altında doğum öncesinde kadınları anneliğe hazırlayan programların içerisinde, annenin bedensel hazırlığı ve gereksinimlerine yönelik eğitimler verilmektedir. Gerek bu programlarda, gerekse birinci basamak sağlık kuruluşlarında (aile hekimliği) psikolojik olarak ileri desteğe gereksinim duyabilecek gebelerin belirlenip doğru şekilde yönlendirilmesinin, toplum ve özellikle anne sağlığı açısından yararlı katkıları olacağı inancındayız.

Yaptığımız çalışmanın bazı kısıtlılıkları mevcuttur. Kesitsel çalışmamızdaki örneklem grupları arasında belirgin sayı farkının olması, bazı değişkenler açısından gruplar arasında fark bulunmamasının nedeni olabilir. Gebeler anket çalışması üzerinden değerlendirilmiş, ancak poliklinik şartlarında psikiyatri uzmanı tarafından muayeneleri yapılamadığından, klinik depresyon tanısı konulmamıştır. Depresyon için yapılan değerlendirmeler ve yorumlar BDÖ üzerinden yapılmıştır. Bazı bedensel veya ruhsal başka hastalığın etkisine bağlı belirtilerin depresyon belirtileri ile karışabildiği gösterilmiştir ${ }^{21}$. Ayrıca, genetik, psikososyal, çevresel değişkenlerden ölçmediğimiz birçok neden, depresyon belirtileri ile ilişkili olabilir22. Sağlık hizmeti sunulan kurumlarda gebeler depresyon belirtileri açısından değerlendirilirken, olabildiğince çok sayıda değişkenin göz önünde bulundurulması gerekmektedir. 
Sonuç olarak, gebeliği sağlıklı ilerleyen olgularda da, değişik bireysel özelliklerin depresyon semptomları gelişimine neden olabileceğini gördük. Antenatal dönemde belirlenmiş sağlık sorunu olmayan gebelerin deprese ruh hâlini arttırabilecek faktörlerin önceden tanınması, anne ve çocuk sağlığını iyileştirici önlemlerin alınmasına yardımcı olabilir.

\section{TEŞEKKÜR}

Çalışmamıza bilgisayar destekli istatistiksel yardı$\mathrm{mı}$ için Eskişehir Osmangazi Üniversitesi Bilgisayar ve Öğretim Teknolojileri Bölümünden Yard. Doç. Dr. Mehmet Ersoy’a teşekkürlerimizi sunarız.

\section{KAYNAKLAR}

1. Stewart D. Depression during pregnancy. Can Fam Physician 2005;51(8):1061-1063.

2. Muzik M, Marcus SM, Heringhausen JE, Flynn H. When depression complicates childbearing: guidelines for screening and treatment during antenatal and postpartum obstetric care. Obstet Gynecol Clin North Am 2009;36(4):771-88. http://dx.doi.org/10.1016/j.ogc.2009.10.006

3. Bennett HA, Einarson A, Taddio A, et al. Prevalence of depression during pregnancy: systematic review. Obstet Gynecol 2004;103(4):698-709. http://dx.doi.org/10.1097/01.AOG.0000116689.75396.5f

4. Llewellyn AM, Stowe ZN, Nemerrof CB. Depression during pregnancy and the puerperium. J Clin Psychiatry 1997;58(Suppl 15):26-32.

5. Çelik F, Nadirgil Köken G, Yılmazer M. Prevalence of depression during pregnancy and the effecting factors. Anatol J Clin Investig 2013;7(2):110-117.

6. Robertson E, Grace S, Wallington T, Stewart DE. Antenatal risk factors for postpartum depression: a synthesis of recent literature. Gen Hosp Psychiatry 2004;26(4):289-295. http://dx.doi.org/10.1016/j.genhosppsych.2004.02.006

7. Beck AT, Ward CH, Mendelson M, et al. An Inventory For Measuring Depression. Arch Gen Psychiatry 1961;4(6):561-71. http://dx.doi.org/10.1001/archpsyc.1961.01710120031004

8. Hisli N. The validity and reliability of Beck Depression Inventory for college students. The Journal of Psychology 1989;2(7):3-13.
9. Savaşır I, Şahin NH (Eds.). Assessment in cognitive and behavioural therapies; Frequently Used Scales. Ankara: Turkish Psychologist Association; 1997. p.100-114. ISBN: 975-975609-5.

10. Erbil N, Oruç $H$, Karabulut A. Determination of depression and affecting factors in pregnancy. Turkiye Klinikleri Journal of Gynecol and Obstet 2009;19(2):67-74.

11. Yeşilçiçek Çalık K, Aktaş S. Depression in Pregnancy: Prevalence, Risk Factors and Treatment. Current Approaches in Psychiatry 2011;3(1):142-162.

12. Şahin EM, Kılıçarslan S. Depressive, anxiety levels and affecting factors of third trimester pregnant women. Trakya Univ Tıp Fak Derg 2010;27(1):51-58.

13. Gotlib IH, Whiffen VE, Mount JH, et al. Prevalence rates and demographic characteristics associated with depression in pregnancy and the postpartum. J Consult Clin Psychol 1989;57(2):269-74. http://dx.doi.org/10.1037/0022-006X.57.2.269

14. Kitamura T, Shima S, Sugawara M, Toda MA. Psychological and social correlates of the onset of affective disorders among pregnant women. Psychol Med 1993;23(4):967-75 http://dx.doi.org/10.1017/S003329170002643X

15. Aubin HJ, Tilikete S, Barrucand D. Depression and smoking. Encephale 1996;22(1):17-22.

16. Ersoy E, Karasu Y, Yaşar Çelik E, Ersoy AÖ, Tokmak A, Taşçı $Y$. Individual features and contraceptive attitudes of women who had unintended pregnancy. Journal of Clinical and Experimental Investigations 2015;6(3):250-255. http://dx.doi.org/10.5799/ahinjs.01.2015.03.0528

17. Kurçer MA, Keleş E. Comparisons effects of smoking and some problems in pregnancy on postpartum depressive symptoms in first and $60^{\text {th }}$ day after birth. TAF Preventive Medicine Bulletin 2009;8(4):323-8.

18. Özeren IA, Atila D, Helvacı M. Premenstrual syndrome and its relationship with depression by the health care employees. The Journal of Tepecik Teaching Hospital 2013;23(1):25-33. http://dx.doi.org/10.5222/terh.2013.68585

19. Yücel U, Bilge A, Oran N, et al. The prevalence of premenstrual syndrome and its relationship with depression risk in adolescents. Anatolian Journal of Psychiatry 2009;10(1):55-61.

20. Field T, Diego M, Dieter J, et al. Prenatal depression effects on the fetus and newborn. Infant Behav Dev 2004;27(2):216229.

http://dx.doi.org/10.1016/j.infbeh.2006.03.003

21. Tezcan E. The differential diagnosis of the depression. Affective Disorders Series 2000;1(2):77-98.

22. Kuehner C. Gender differences in unipolar depression: An update of epidemiological findings and possible explanations. Acta Psychiatr Scand 2003;108(3):163-17. http://dx.doi.org/10.1034/j.1600-0447.2003.00204.x 